\title{
EVALUATION OF SUITABILITY TO USE PLASTIC WASTE IN CONCRETE PRODUCTION
}

Rytis SKOMINAS, Institute of Hydraulic Engineering, Aleksandras Stulginskis University, Universiteto 10, LT-53361, Akademija, Kaunas dist., Lithuania, rytis.skominas@asu.lt (corresponding author)

Linas ZVINAKEVIČIUS, Institute of Hydraulic Engineering, Aleksandras Stulginskis University, Address: Universiteto 10, LT53361, Akademija, Kaunas dist., Lithuania, hsi@asu.lt

Vincas GURSKIS, Institute of Hydraulic Engineering, Aleksandras Stulginskis University, Universiteto 10, LT-53361, Akademija, Kaunas dist., Lithuania, vincas.gurskis@asu.lt

Raimondas ŠADZEVIČIUS, Institute of Hydraulic Engineering, Aleksandras Stulginskis University. Universiteto str. 10, LT-53361 Akademija, Kaunas distr, Lithuania, raimondas.sadzevicius@asu.lt

Nowadays one of the main tasks of environmental protection is the management and recycling of plastic waste. Plastic occupy the major part of all public waste and with this material is polluted all earth. In natural condition plastic decompose in 400 or even in 500 years. Therefore, it is important to solve this problem reusing plastic waste. One of the possible areas is construction industry. In the present paper were estimated how plastic waste impact the properties of concrete. During the research the part of coarse aggregates were changed with polyethylene (PE) pellets and cut polypropylene (PP) particles. The change of fresh concrete density, workability and hardened concrete density, compression strength, water absorbability were evaluated. The results show, that plastic waste has a positive effect on fresh concrete properties: the concrete become more workable and lighter. Unfortunately, on the main hardened concrete properties the increase plastic waste amount has the negative effect: the compression strength was decreasing and the water absorbability was increasing. However, generalizing all results, can be stated, that keeping the same level of concrete workability there are possibilities to reduce water and cement ratio and it will give strength loss and water absorbability growth compensation.

Keywords: aggregates, compression strength, concrete, plastic waste, water absorbability, workability.

\section{INTRODUCTION}

Nowadays plastic is our daily material. We can find it almost everywhere: appliances are made from plastic; food has plastic package and etc. Every year the production of plastic is increasing. For example, during the last 50 years the amount of plastic manufacture increased from 1.5 mio. t/year to 322 mio. t/year (Statista..., 2017). And this is not a limit.

The increasing usage and too low reusing of plastic determine that this material has a huge influence on earth geology. From 322 million tons of manufactured plastic, one third parts are throwing out after usage. The major part of plastic waste goes to dumps, where is leaving for long-term decay, the part goes to recycling and the part of plastic come to the oceans.

Plastic waste recycling is very important process in harmonious waste management. One of many opportunities is to use plastic waste in construction process. For example, it is possible to use plastic waste as aggregates in concrete production. Such case will let us to safe natural resources: sand, gravel, break-stone and will reduce $\mathrm{CO}_{2}$ emission.

Recently there are made many research works in this field. It is possible to find a lot of results about fibres made from plastic waste. From this group can be mentioned Algeria scientist work (Ghernouti et al., 2015), where fibres were made from plastic bag waste.

The Turkey scientist made an investigations (Gesoglu el al., 2017) on the mechanical and fracture properties of self-compacting concretes containing plastic waste powder in varying amounts used as a cement replacement material. Partial amount of cement was replaced by plastic waste powder at 5\%,10\%, 15\%, 20\% and 25\% by weight. The results show that the compressive strength of self-compacting concretes was adversely influenced by using plastic waste powder. However, the highest reduction did not exceed $24.6 \%$ at $25 \%$ plastic waste replacement level.

S. M. Hama and N. N. Hilal in their research (2017) were looking to find out the effectiveness of using plastic waste as partial replacement of fine aggregate on self-compacting concrete. The six designated plastic waste contents of $0,2.5,5$, $7.5,10$, and $12.5 \%$ and three different sized Plastic wastes (fine plastic wastes, coarse plastic wastes, and mixed plastic waste) were considered as experimental parameters. The experimental results of this work showed that the plastic waste with the sizes and contents that used in this work can be used successfully as a fine aggregate in self-compacting concrete.

Also there are some interesting scientific works which recommend using plastic bottles (PET) replacing traditional concrete blocks (Mansour et al., 2015; Safinia et al., 2016).

Copyright (C) 2017 The Authors. Published by Aleksandras Stulginskis University. This is an open-access article distributed under the terms of the Creative Commons Attribution License (CC-BY 4.0), which permits unrestricted use, distribution, and reproduction in any medium, provided the original author and source are credited. 
There more scientific works (Correia et al., 2014; Ruiz - Herrero et al., 2016; Silva et al., 2013; Yang et al., 2015) where is recommended to use plastic waste as concrete aggregates, however it is missing more detailed data about different plastic waste influence on concrete properties.

The aim of the research is to estimate how plastic waste used as coarse aggregates impact the properties of concrete.

\section{MATERIALS} in concrete.

During the research two types of plastic waste were used to reduce the amount of natural resources (crushed gravel)

As the first type of plastic were used PE pellets. These pellets were made from PE waste such as PET bottles and bags. The bulk density of PE pellets was $548 \mathrm{~kg} / \mathrm{m}^{3}$, porosity $-41 \%$.

As the second type of plastic was used cut PP waste (car bumpers). The bulk density of cut PP particles was $377 \mathrm{~kg} / \mathrm{m}^{3}$, porosity $-59 \%$.

Concrete was prepared using cement CEM II/A-L 42,5 N, coarse aggregate - crushed gravel (fraction $4 \ldots 16 \mathrm{~mm}$ ) and fine aggregate - sand (fraction $0 \ldots 4 \mathrm{~mm}$ ), the water-cement ratio $\mathrm{W} / \mathrm{C}=0.5$. Aggregates and water meet the requirements described in European standards EN 12620:2002+A1:2008 and EN 1008:2002.

The class of control concrete (without plastic waste) was selected quite high - C30/37, in purpose, correctly to estimate the impact of plastic waste on concrete properties.

\section{TEST METHODS}

The density and consistency of fresh concrete was estimated according to standard methods (EN 12350-6:2009, EN 12350-2:2009 and EN 12350-5:2009). The compression strength, and water absorbability of hardened concrete were established according to standard methods (EN 12390-3:2009, EN 13369:2004). The size of tested concrete specimens was $100 \times 100 \times 100 \mathrm{~mm}$ with the age of 28 days. Test of fresh and hardened concrete were applied to control concrete and concrete with partly changed coarse aggregates to plastic waste. With the PE pellets and PP cut particles were changed $5,10,15,20$ and $25 \%$ of coarse aggregates according to bulk density.

\section{TEST RESULTS}

At the beginning of the research were estimated how plastic waste impact on the properties of fresh concrete. The test results (Fig. 1) show that increasing the amount of plastic in concrete the density of fresh concrete decreases. For example, when $25 \%$ of coarse aggregates were changed to PE pellets the density of fresh concrete decreased approximately by $10 \%$ and when to PP cut particles the density decreased approximately by $11 \%$. This decrease is related to differences between plastic density and density of the particles of coarse aggregates (granite, dolomite, limestone). The natural density of PE and PP is $855 \ldots 960 \mathrm{~kg} / \mathrm{m}^{3}$ and the natural density of granite, dolomite and limestone is $2160 \ldots 2750 \mathrm{~kg} / \mathrm{m}^{3}$. So, it is more than two times less. The decrease of fresh concrete density is positive effect (if there are no changes in other properties), because the mass of fresh concrete decreases. For example, if we have concrete mixer truck with $10 \mathrm{~m}^{3}$ capacity, the weight of transporting concrete, with $25 \%$ changed coarse aggregates, will be more 2000 $\mathrm{kg}$ less. This weigh difference will save fuel costs.

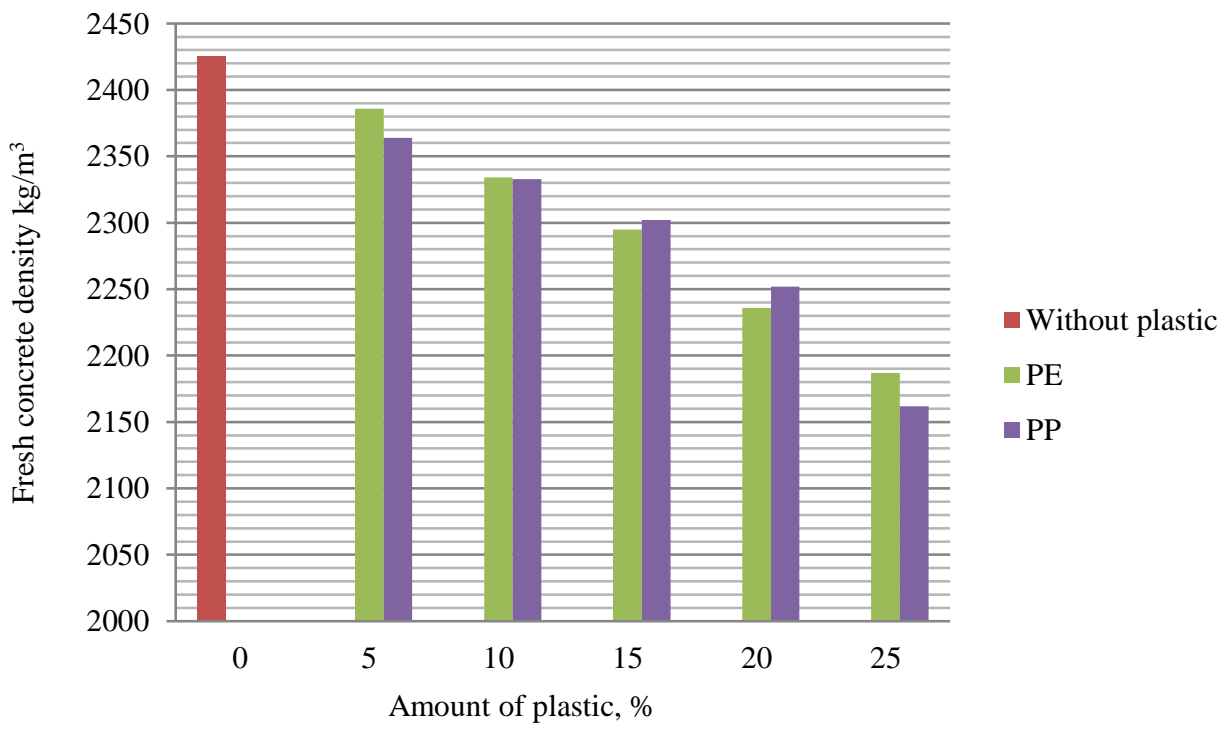

Figure. 1. Plastic waste impact on fresh concrete density 
The increasing plastics amount has effect on fresh concrete consistency too (Table 1 and 2). During the research were estimated that fresh concrete with more than $10 \%$ changed coarse aggregates to PE pellets is too plastic for the slump test, therefore this method was changed to flow table test. The test results show that the fresh concrete with more plastic waste has higher workability. Using $25 \%$ of PE pellet the consistency of fresh concrete become from stiff to freeflowing and using $25 \%$ of cut PP waste become very soft. Having such workability these fresh concretes (with $25 \%$ plastic waste) is suitable for structures with congested reinforcement.

Table 1. Slump test results

Table 1. Slump test results
\begin{tabular}{|c|c|c|c|c|}
\hline $\begin{array}{c}\text { Amount of coarse } \\
\text { aggregates changed to } \\
\text { plastic waste, } \%\end{array}$ & Plastic type & Slump, mm & Class & $\begin{array}{c}\text { Description of } \\
\text { consistency }\end{array}$ \\
\hline 0 & none & 40 & S1 & Stiff \\
\hline \multirow{2}{*}{5} & PE & 50 & S2 & Plastic \\
\cline { 2 - 5 } & PP & 40 & S2 & Stiff \\
\cline { 2 - 5 } & PE & 80 & S2 & Plastic \\
\hline
\end{tabular}

Table 2. Flow table test results

\begin{tabular}{|c|c|c|c|c|}
\hline $\begin{array}{c}\text { Amount of coarse } \\
\text { aggregates changed to } \\
\text { plastic waste, } \%\end{array}$ & Plastic type & Spread, mm & Class & $\begin{array}{c}\text { Description of } \\
\text { consistency }\end{array}$ \\
\hline \multirow{2}{*}{15} & PE & 510 & F4 & Very soft \\
\cline { 2 - 5 } & PP & 410 & F2 & Plastic \\
\hline \multirow{2}{*}{20} & PE & 540 & F4 & Very soft \\
\hline \multirow{2}{*}{25} & PP & 450 & F3 & Foft \\
\cline { 2 - 5 } & PE & 580 & F4 & Very soft \\
\hline
\end{tabular}

In order to estimate the influence of plastic waste on properties of hardened concrete, density, compression strength and water absorbability were established. The test results (Fig. 2) show that increasing the amount of plastic in concrete the density of hardened concrete decreases. The density of hardened concrete is related to the density of fresh concrete and the reason of decrease is the same. This occurrence for hardened concrete is positive, because the weight of structures is decreasing too. Due to this effect dead loads are decreasing and the structures can be designed smaller.

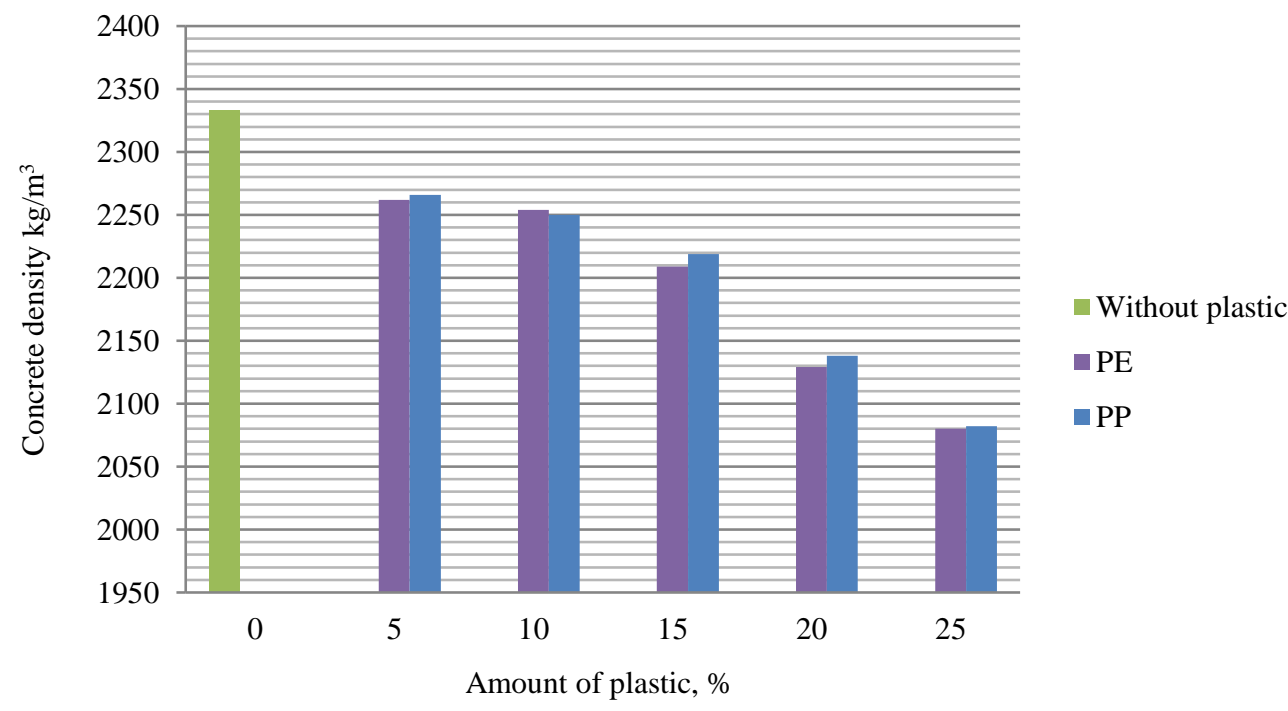

Figure 2. Plastic waste impact on hardened concrete density

From the compression strength test results (Table 3, Fig. 3) can be summarized, that increasing plastic amount in concrete have a negative effect on this property. For example, changing $25 \%$ of coarse aggregates to cut PP waste the strength loss will be about $25 \%$ (the concrete class will decrease from C30/37 to C20/25) and changing to PE pellets the strength loss will be about $40 \%$ (the concrete class will decrease from C30/37 to C16/20). However, small amount of plastic is not so dangerous - the strength loss of concrete with $5 \%$ cut PP waste will be up to $5 \%$ and the strength loss of concrete with $5 \%$ PE pellets will be up to $8 \%$. Comparing the influence of different plastics on concrete strength it was estimated that cut PP waste show better results. This effect can be explained, that PP particles has irregular form and larger surface area. Therefore, they have better adhesive with the cement paste. 
Table 3. Compression strength test results

\begin{tabular}{|c|c|c|c|c|}
\hline $\begin{array}{l}\text { Amount of coarse } \\
\text { aggregates changed to } \\
\text { plastic waste, } \%\end{array}$ & Plastic type & $\begin{array}{c}\text { Compression strength, } \\
\mathrm{MPa}\end{array}$ & Class & Strength loss, $\%$ \\
\hline 0 & none & 43.6 & C30/37 & - \\
\hline \multirow{2}{*}{5} & $\mathrm{PE}$ & 40.3 & $\mathrm{C} 25 / 30$ & 7.6 \\
\hline & $\mathrm{PP}$ & 41.7 & $\mathrm{C} 30 / 37$ & 4.4 \\
\hline \multirow{2}{*}{10} & $\mathrm{PE}$ & 39.0 & $\mathrm{C} 25 / 30$ & 10.6 \\
\hline & $\mathrm{PP}$ & 39.7 & $\mathrm{C} 25 / 30$ & 8.9 \\
\hline \multirow{2}{*}{15} & $\mathrm{PE}$ & 31.4 & $\mathrm{C} 20 / 25$ & 28.0 \\
\hline & $\mathrm{PP}$ & 38.7 & $\mathrm{C} 25 / 30$ & 11.2 \\
\hline \multirow{2}{*}{20} & $\mathrm{PE}$ & 30.3 & $\mathrm{C} 20 / 25$ & 30.5 \\
\hline & PP & 35.3 & $\mathrm{C} 25 / 30$ & 19.0 \\
\hline \multirow{2}{*}{25} & $\mathrm{PE}$ & 26.9 & $\mathrm{C} 16 / 20$ & 38.3 \\
\hline & PP & 32.9 & $\mathrm{C} 20 / 25$ & 24.5 \\
\hline
\end{tabular}

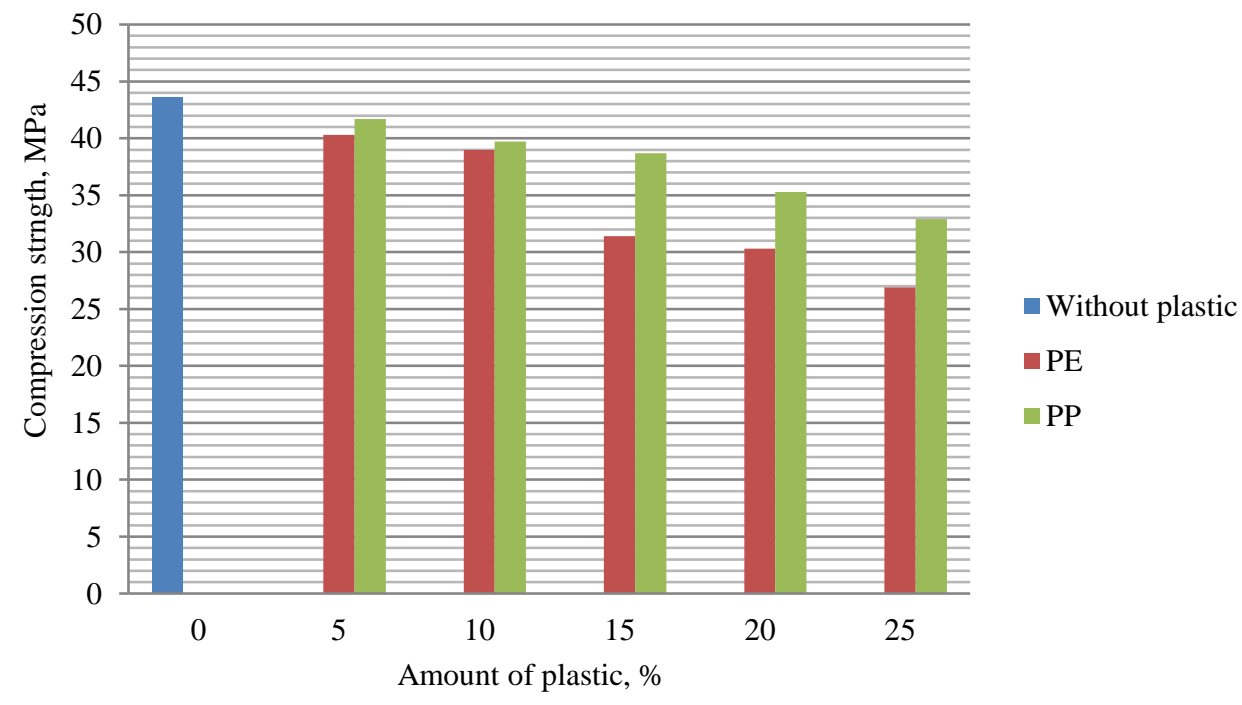

Figure 3. Plastic waste impact on concrete strength

The plastic also have a negative effect on water absorbability of concrete (Fig. 4). The increasing amount of plastic in concrete increases the water absorbability too. The plastic is non-absorbable material, therefore all water spread in less volume. This effect impacts the workability (concrete mixture become more plastic) and during the hardening process in less volume is forming more capillaries and pores.

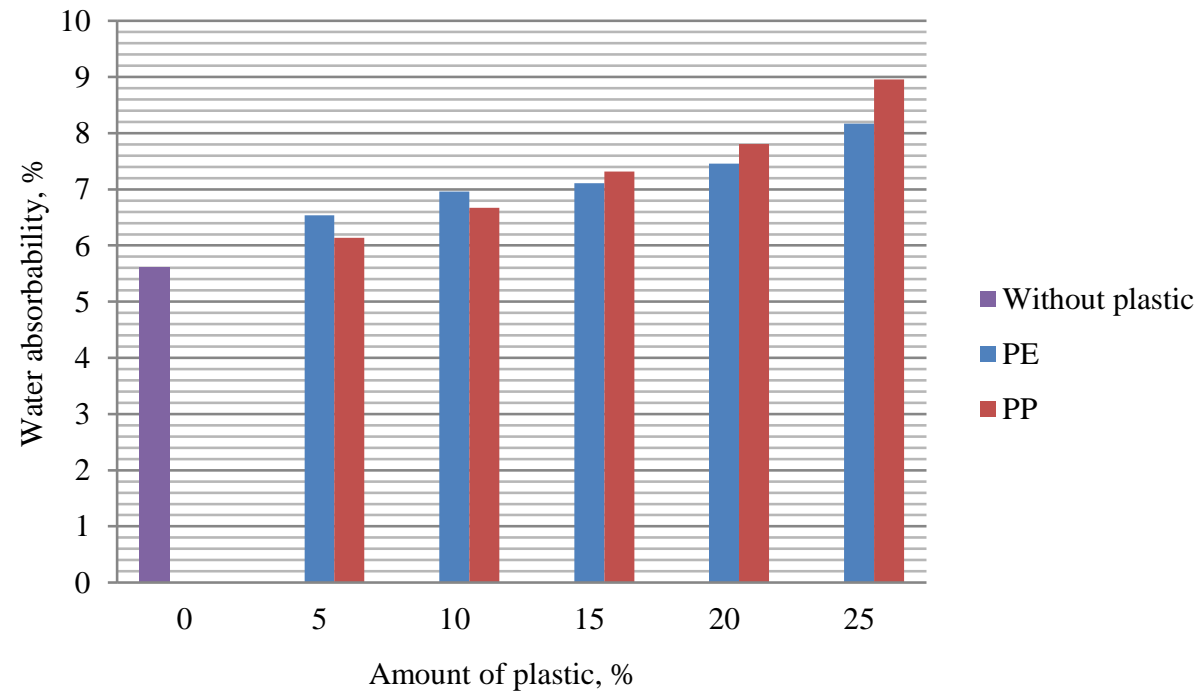

Figure 4. Plastic waste impact on concrete water absorbability 
Generalizing all results can be stated that partly changing natural coarse aggregates to plastic waste aggregates, the concrete density and strength is decreasing, while concrete workability and water absorbability is decreasing. To reduce a negative effect on concrete strength and water absorbability it is possible reducing the amount of water (keeping the constant workability). The decreasing water and cement ratio will increase concrete strength and decrease water absorbability. However, this hypothesis must be checked in further investigations.

\section{CONCLUSIONS}

1. The increasing plastic waste amount has a positive effect on fresh concrete properties. The concrete become lighter and more workable. Changing $25 \%$ of coarse aggregates to plastic waste, the density of fresh concrete decreased by $10 \%$ and fresh concrete from stiff consistency became very soft (using cut PP waste) and free-flowing (using PE pallets).

2. The plastic waste has negative effect on concrete compression strength and water absorbability. However, small amount of plastic is not so dangerous for concrete and it is possible to reduce negative effect reducing water and cement ratio (keeping the constant workability).

3. Comparing the influence of different plastics on concrete strength it was estimated that cut PP waste show better results. This effect can be explained, that PP particles has irregular form and lager surface area like PE pellets.

\section{REFERENCES}

1. Correia, J.R., Lima, J.S., De Brito, J. 2014. Post-fire mechanical performance of concrete made with selected plastic waste aggregates. Cement \& Concrete Composites, Vol. 53, pp. 187-99. https://doi.org/10.1016/j.cemconcomp.2014.07.004

2. EN 1008:2002 Mixing water for concrete - Specification for sampling, testing and assessing the suitability of water, including water recovered from processes in the concrete industry, as mixing water for concrete.

3. EN 12350-2:2009 Testing fresh concrete - Part 2: Slump-test.

4. EN 12350-5:2009 Testing fresh concrete - Part 5: Flow table test.

5. EN 12350-6:2009 Testing fresh concrete - Part 6: Density.

6. EN 12390-3:2009 Testing hardened concrete - Part 3: Compressive strength of test specimens.

7. EN 12620:2002+A1:2008 Aggregates for concrete.

8. EN 13369:2013 Common rules for precast concrete products.

9. Gesoglu, M., Güneyisi, E., Hansu, E., Etli, S., Alhassan, M. 2017. Mechanical and fracture characteristics of self-compacting concretes containing different percentage of plastic waste powder. Construction and Building Materials, Vol. 140, pp. 562-569. https://doi.org/10.1016/j.conbuildmat.2017.02.139

10. Ghernouti, Y., Rabehi, B., Bouziani, T., Ghezraoui, H., Makhloufi, A. 2015. Fresh and hardened properties of self-compacting concrete containing plastic bag waste fibers (WFSCC). Construction and Building Materials, Vol. 82, pp. 89-100. https://doi.org/10.1016/j.conbuildmat.2015.02.059

11. Hama, S.M., Hilal, N.N. 2017. Fresh properties of self-compacting concrete with plastic waste as partial replacement of sand. International Journal of Sustainable Built Environment. https://doi.org/10.1016/j.ijsbe.2017.01.001

12. Mansour, A.M.H., Ali, S.A. 2015. Reusing waste plastic bottles as an alternative sustainable building material. Energy for Sustainable Development, Vol. 24, pp. 79-85.

13. Ruiz-Herrero, J.L., Nieto, D.V., Lopez-Gil, A., Arranz, A., Fernandez, A., Lorenzana, A., Merino, S., De Saja, J.A., RodriguezPerez, M.A. 2016. Mechanical and thermal performance of concrete and mortar cellular materials containing plastic waste. Construction and Building Materials, Vol. 104, pp. 298-310. https://doi.org/10.1016/j.conbuildmat.2015.12.005

14. Safinia, S., Alkalbani, A. 2016. Use of recycled plastic water bottles in concrete blocks. Procedia Engineering, Vol. 164, pp. 214-221. https://doi.org/10.1016/j.proeng.2016.11.612

15. Silva, R.V., De Brito, J., Saikia, N. 2013. Influence of curing conditions on the durability-related performance of concrete made with selected plastic waste aggregates. Cement \& Concrete Composites, Vol. 35, pp. $23-31$. https://doi.org/10.1016/j.cemconcomp.2012.08.017

16. Statista. 2017. Available at https://www.statista.com/statistics/282732/global-production-of-plastics-since-1950/

17. Yang, S., Yue, X., Liu X., Tong Y. 2015. Properties of self-compacting lightweight concrete containing recycled plastic particles. Construction and Building Materials, Vol. 84, pp. 444-453. https://doi.org/10.1016/j.conbuildmat.2015.03.038 